\title{
Research on the Impact of Expressway on the County Economy Based on a Spatial DID Model: The Case of Three Provinces of China
}

\author{
Xueming $X u \mathbb{D}^{1,2}$ and Changping Liu ${ }^{3}$ \\ ${ }^{1}$ Beijing Key Laboratory of Traffic Engineering, Beijing University of Technology, Beijing 100124, China \\ ${ }^{2}$ CCCC Highway Consultants Co., Ltd., Beijing 100088, China \\ ${ }^{3}$ Beijing Transport Institute, Beijing 100073, China
}

Correspondence should be addressed to Xueming Xu; xuxueming@hpdi.com.cn

Received 7 July 2020; Revised 31 March 2021; Accepted 13 May 2021; Published 21 May 2021

Academic Editor: Emilio Jiménez Macías

Copyright ( $) 2021$ Xueming Xu and Changping Liu. This is an open access article distributed under the Creative Commons Attribution License, which permits unrestricted use, distribution, and reproduction in any medium, provided the original work is properly cited.

\begin{abstract}
Infrastructure construction results in transportation cost and regional economy changes. Based on the exogenous infrastructure change of a county highway opening as a natural experiment, this paper uses the spatial difference-in-differences (DID) model to analyze the impact of highway construction in three different provinces of China from 2004 to 2017. It was proved that highway connectivity had no significant or negative impact on the economy of the counties in three provinces that the highway passes through. In addition, highway connectivity was claimed to have obvious spatial spillover effects, which could promote the economic development of the whole region. For counties belonging to provinces in different regions and stages of economic development, we establish a spatial DID model that integrates time and space dimensions to study the impact of expressways on county economic development, to make up for the traditional DID model's dependence on SUTVA assumptions, and to obtain spatial spillover effects.
\end{abstract}

\section{Introduction}

The role of transportation infrastructure in promoting and guiding economic development is recognized across the world, in which the expressway, as effective infrastructure to improve transport efficiency, has played a huge role in promoting the development of the regional economy. Therefore, it has attracted the attention of governments and scholars [1]. China began expressway construction in 1984. After more than 30 years of development, the total mileage of expressways in China reached $142,600 \mathrm{~km}$ by the end of 2018 , which meant that it ranked first in the world. A large-scale highway system requires a huge amount of construction and operating expenses. As a result, it is particularly important to analyze the impact of expressways on economic development.
Recent research has analyzed the impact of transport infrastructure construction on the economy at the national, state, or interprovincial level, while its impact from a smaller intercounty perspective has rarely been analyzed. The county economy is not only the basic unit of the national economy but also an important part of the economy in China. In terms of the total economic output, the gross domestic product of 2079 counties in 2017 totaled 43.635461 trillion yuan in China, accounting for $52.4 \%$ of the total GDP in that year. In terms of the growth rate, the Chinese county economy grew at an average annual rate of $16.04 \%$ from 2003 to 2015, while the Chinese economy grew at an average annual rate of 9.81\% during the same period [2]. It can be concluded from the above data that the county economy not only accounts for more than half of the Chinese total economic volume but is also an important factor through which the country can maintain rapid economic growth. Therefore, it is important 
to analyze the impact of highway construction on economic development from the perspective of the county economy.

The main contributions of the paper can be summarized in the following three aspects. First, we select the counties of different provinces in different locations and stages of economic development in China to ensure that the research objects have sufficient coverage and relevance; at the same time, the panel data time span reaches 14 years, which can realize local economic development changes. Secondly, a parallel trend test was fully carried out to ensure that the control group and the experimental group have the common trend to ensure that the impact of highway construction is reflected. Third, the economic geography matrix is introduced as the spatial weight matrix, which reflects the influence of distance and economic development, making the research more reasonable.

The rest of the paper is organized as follows. Section 2 provides relevant literature review. Section 3 describes the necessary background. Section 4 contains model structure and data in detail. Section 5 shows the method and result of the parallel trend test. Section 6 contains setting of the spatial weight matrix. Section 7 shows and discusses the empirical results. The last section concludes.

\section{Literature Review}

As an important part of infrastructure, transport infrastructure plays an important basic and leading role in economic development. With the deepening of research on economic growth theory in recent years, the impact of transport infrastructure as an important research topic has received plenty of attention.

Aschauer adopted the Cobb-Douglas production function (C-D production function). Through an analysis of the time series and cross-sectional data from 1945 to 1985 in the United States, Aschauer claimed that government investment in infrastructure has contributed to the growth of the total economic output [3]. Using the data of the counties of California from 1968 to 1988, Boarnet believed that the areas with better transportation infrastructure would attract the resources of the surrounding areas, which would result in negative spillover effects [4]. Khadaroo and Seetanah studied the association between transport capital and economic growth for Mauritius from 1950 to 2000 and found that transport infrastructure has significantly contributed to the economic performance [5]. Khadaroo and Seetanah used the ARDL approach to analyze data of Mauritius from 1960 to 2004 and found that transport infrastructure availability is seen to have contributed to the relative attractiveness of the country towards FDI [6]. Pradhan et al. analyzed the impact of transport infrastructure on India's economic growth from 1970 to 2010 and found that there was a two-way causal relationship between transport infrastructure and economic growth: the expansion of transport infrastructure and the growth of total capital led to a substantial growth of the Indian economy [7]. Therefore, it was suggested that transport policies be retained to stimulate the growth of transport infrastructure investment and promote economic growth. Sanchez et al. investigated the data from OECD countries and found that transport infrastructure promoted economic growth by indirectly increasing environmental consumption, but did not directly generate economic growth [8]. Chi studied the effectiveness of transport infrastructure investment in improving the economy and found that expanding transport infrastructure investment may be an effective way to improve the economic level of developing European economies [9]. Crescenzi et al. assessed the relationship between government regional quality and profits of different types of road infrastructure in the European Union (EU) region and concluded that although the government preferred highways, the benefits were lower than that of secondary roads [10]. Kalra et al. conducted an empirical analysis on the relationship between transport infrastructure and economic growth in India and found that there was both a short-term and a two-way causal relationship between GDP and transport infrastructure [11]. Mohmand et al. believed that the development of transport infrastructure could directly or indirectly affect economic growth [12]. Additionally, transport infrastructure construction could bring trade and investment opportunities to previously underdeveloped regions, as well as goods transport, services, and employment opportunities through these multiplier effects. Yapicioglu et al. conducted questionnaires on public entities, private clients, consultants, and contractors in the construction industry in six Nigerian states [13]. They found that while transport policies improved transport infrastructure investment, they also promoted sustainable economic development. Saidi et al. discussed the impact of transport energy consumption and transport infrastructure on economic growth in the Middle East and North Africa [14]. They found that the development of transport infrastructure had a positive impact on the economic growth in all regions, while transport energy consumption promoted economic growth in only a few regions. Tong and Iop discussed the relationship between GDP and road transport infrastructure density of 12 cities in Inner Mongolia and analyzed the relationship between economic growth and road transport infrastructure [15]. They found that the promotion of road transport infrastructure to economic growth is permanent, and the impact of road transport infrastructure on economic growth increased gradually and then weakened gradually after reaching the peak. Wang et al. used the nearest neighbor distance method, kernel density estimation, regression analysis, global autocorrelation, local autocorrelation, and other spatial methods to study the spatial distribution characteristics and growth mechanisms of 238 megacities in China [16]. Baumsnow et al. investigated the effects of the recently constructed Chinese national highway system on local economic outcomes [17]. They found that, with the development of expressways, the economic output and population of advantageous areas increased, while the interests of hinterland areas declined, which had an impact on the regional economic structure. Herzog estimated inter-regional transportation's effect on the local economic activity by studying the Interstate Highway System and found that interstates' effects were highly heterogeneous and that additions to early Interstate plans were less valuable than the system's core [18].

Summarizing recent research findings, Liu and Zhou used Chinese county-level panel data for the first time to investigate the impact of highway construction on the 
county-level economy from 1997 to 2008 [19]. They found that expressways have a significant positive impact on the county economy. However, Faber analyzed the county-level economic data to discuss the highway built in China from 1998 to 2003 and the county-level economic data from the 1997-2006 period [20]. It was found that the highway had a significant negative effect on connecting the small counties. Dong and Liu concluded that the connectivity of national highways had a significant positive impact on the economy of the counties through which the national expressway passed from 2004 to 2013 [21]. They also claimed that the farther away one is from a major city, the smaller the county seat is affected by the positive driving effect. The spatial spillover effects of expressways were not taken into account in the above discussion, although it was proved that the traffic infrastructure has significant externalities. Therefore, the spatial spillover effects of expressways need to be fully considered. Moreover, the difference-in-differences (DID) model used in the above research has relatively strict application conditions, and it is evident that the characteristics of traffic infrastructure conflicted with the conditions; thus, such research methods need to be improved.

\section{Theoretical Basis of the Spatial DID Model}

3.1. The DID Model. The DID model is widely used in econometrics to quantitatively evaluate the implementation of public policies or projects [22]. Its core idea is to realize an effective analysis of the implementation effect of a policy or project through the natural experimental construction of "difference before and after" and "with or without contrast." Its theoretical model is shown in the following formula:

$$
\begin{aligned}
\beta^{\mathrm{DID}}= & \left(Y^{\text {treat, after }}-\bar{Y}^{\text {treat, before }}\right) \\
& -\left(\bar{Y}^{\text {control, after }}-\bar{Y}^{\text {control, before }}\right),
\end{aligned}
$$

where $\beta$ is the DID estimator, $Y$ is the outcome variable in the study, "treat" and "control" represent the experimental group and control group, respectively, and "before" and "after" represent preintervention and postintervention, respectively. The DID method effectively eliminates the impact of nonproject factors, so it is widely used to assess the impact of policy or project implementation on the regional economy.

The form of the DID model is shown as follows:

$$
Y_{i t}=\beta_{0}+\beta_{1} D_{i t}+\beta_{2} T_{i t}+\beta_{3} T_{i t} \times D_{i t}+X_{i t}+\alpha_{i}+\varepsilon_{i t},
$$

where $D_{i t}$ and $T_{i t}$ are virtual variables, the value of which can only be 0 or 1 . They represent whether the object is the treatment group or the control group and whether the time is before or after implementation.

The DID model takes the implementation time of the public policy or project as a clear sign to distinguish before and after the intervention, and there is a clear single time point. However, within the scope of the study, when there are inconsistencies in the policy implementation or project completion time in different regions, it is necessary to introduce a multiperiod DID model.
The multiperiod DID model takes the interaction terms of $D_{i t}$ and $T_{i t}$ in the DID model as the symbol of policy or project implementation. In the multiperiod DID model, there is only the interactive term of the product of two virtual variables, while the separate terms of $D_{i t}$ and $T_{i t}$ are not included. The form of the multiperiod DID model is as follows:

$$
Y_{i t}=\beta_{0}+\beta_{1} T_{i t} \times D_{i t}+X_{i t}+\alpha+\varepsilon_{i t} .
$$

The problem of an inconsistent implementation time can be solved effectively by using the multiperiod DID model, and the application range of the DID model can be greatly improved. In addition, the sample size can be greatly increased by stages. Even if the final policy or project covers all of the objects, the objects in the period in which the policy or project has not yet been implemented can still be used as the control group.

\subsection{Application of the DID Model in Transportation.} Based on the above characteristics, the DID model has been widely used to evaluate the impact of traffic infrastructure construction. By using the data of 287 prefecture-level and above cities in China from 2006 to 2010, Wang and Nian used the DID model to empirically test whether the opening of a high-speed railway had a significant impact on the development of the regional economy [23]. By constructing a DID model, Li et al., respectively, took the location entropy of the tertiary industry as the agglomeration economic index to econometrically analyze the impact of a high-speed railway on the urban agglomeration economy [24]. Taking the Yangtze River Delta urban agglomeration as an example, Fang and Sun used the DID model to analyze the impact of high-speed railway construction on the per capita GDP growth rate and the gap between urban and rural areas in the Yangtze River Delta urban agglomeration [25]. Based on the transaction data of 600,000 new houses in Shanghai, Fan et al. used the progressive DID model to analyze the impact of a subway on the housing area and price [26]. Liu, Faber, and Dong Xiaofang used the DID model to analyze the impact of an expressway on regional economic development.

In the above research, domestic and foreign scholars have used double cross-section or panel data to analyze the impact of major traffic infrastructure on the study area by using the DID model or the multiperiod DID model.

3.3. The Spatial DID Model. There is an important assumption when using the DID model, which is the effectiveness of the stable unit treatment value assumption (SUTVA) [27]. This assumption assumes that the potential result of an object will not be affected by others which are being processed [28]. The violation of SUTVA, which is also known as "intervention" or "social interaction," has been a popular research theme of economics and many other disciplines [29]. Traffic infrastructure projects have significant externalities, which need to be paid attention. Therefore, the spatial DID (SDID) model has been introduced. 
Through the spatial econometric model, the spatial interaction of processing utility between objects is described, which effectively solves the problem in the traditional DID model. The spatial DID model fully considers the possibility that the project affects the spatial correlation and allows spatial interaction in the implementation effect of the project. Spatial interaction refers to the direct and indirect effects of policy or project implementation. The indirect effect is referred to as the "spillover effect" or the "network effect." The specific form of the spatial DID model is related to the selection of the spatial lag term, which is introduced in combination with the spatial econometric model below.

After the spatial DID model was proposed, it was applied in many fields, including the impact of traffic infrastructure construction. Dubé et al. used the spatial DID model to analyze the impact of rail transit project construction on the housing prices in the affected area [30]. They took the development of the new rail transit system in the suburbs of Montreal, Canada, as an example and compared it with the traditional DID model. Chagas et al. analyzed the effects of sugarcane yield on respiratory diseases in Brazil using a spatial DID model and proposed a separation method for the effects on production and nonproduction areas [31]. Sunak et al. applied the spatial DID model to analyze the influence of a wind farm on the room under a different landscape influence degree [32]. Based on census data, Zhou et al. used the spatial DID model to discuss whether rail transit promoted the diffusion of industry in Beijing [33].

\section{Spatial DID Model Setting, Variable, and Data}

4.1. Spatial DID Model Setting. The most commonly used spatial econometric models include the spatial autoregressive model (SAR), the spatial error model (SEM), and the spatial Durbin model (SDM). Considering the interregional interaction in economic development and the impact of highway connectivity on economic development, this paper chose the spatial Durbin model (SDM) as the main analysis model and conducted a comparative analysis of the spatial autoregressive model (SAR) and the spatial error model (SEM). According to the construction of the multiperiod DID model, which was introduced in the previous section, the interaction item $D_{t}$, which characterizes the highway connection, is added to the spatial measurement model to form various forms of the spatial DID model. The spatial Durbin DID model is as follows:

$$
Y_{t}=\rho W Y_{t}+\alpha \iota_{N}+X_{t} \beta+W X_{t} \theta+D_{t} \gamma+W D_{t} \eta+\varepsilon_{t} .
$$

The spatial autoregressive DID model is as follows:

$$
Y_{t}=\rho W Y_{t}+\alpha \iota_{N}+X_{t} \beta+D_{t} \gamma+W D_{t} \eta+\varepsilon_{t}
$$

The spatial error DID model is as follows:

$$
Y_{t}=\alpha \iota_{N}+X_{t} \beta+D_{t} \gamma+\mu_{t} \ldots \mu_{t}=\rho W \mu_{t}+\varepsilon_{t},
$$

where $Y_{t}$ is the explained variable, which refers to the economic development of the county in a certain year. This paper used the GDP of the county in the current year to present the changes in the economy. $D_{t}$ is a virtual variable indicating whether the county is connected to the highway in that year. If it is connected in that year, it is set to 1 ; otherwise, it is 0 . The function of $D_{t}$ is equivalent to the interactive term of the traditional DID model. $X_{t}$ is a covariable, which is mainly a statistical index related to the economic development of each research object. $W Y_{t}$ is an endogenous interaction effect between the explanatory variables. $W X_{t}$ is an exogenous interaction effect between the explanatory variables. $\mathrm{Wu}$ is an interaction effect between the interference terms of different observation units. $\rho$ is a spatial autoregressive coefficient. $\lambda$ is a spatial autocorrelation coefficient. $\theta$ and $\beta$ represent fixed and unknown parameter variables to be estimated. $\varepsilon$ is an independent random error term constant. $\iota N$ is a unit vector.

The purpose of this article is to study the impact on economic development after the expressway is connected. It is undoubtedly appropriate to use the DID model for this comparison. The expressway has the function of connecting different areas, and the spatial spillover effect brought about by the construction results is also inevitable. In this case, spatial DID is a more appropriate method.

From the limitation of the method, there is a certain presetting for the setting of the influence form of the spatial indirect effect. And, it has an additive relationship with the direct effect, but whether it is an additive relationship in practice still needs further argumentation and analysis.

4.2. Variables and Data. In order to enhance the representativeness of the study, this paper chose Guangdong province, Hubei province, and Qinghai province as representative provinces of China. Guangdong province, Hubei province, and Qinghai province are located in the eastern, central, and western regions of China, respectively, and can thus represent different geographical locations. In 2017, Guangdong, Hubei, and Qinghai provinces ranked 1st, 7th, and 30th, respectively, in the total GDP of 31 provincial administrative regions in mainland China. Therefore, these three provinces can also reflect three different levels of economic development in China.

In this study, the time of the connected expressway in the county was determined by the statistical data of the opening time of the highway section provided by the local transport authority and the situation of the regional road network. Other economic statistics were obtained from the China County Economic Research Database in CSMAR (Guotai'an CSMAR database) and the 2004-2017 China County Statistical Yearbook.

As described above, the representative interaction item in this paper is the highway connectivity, and the values of this term for Guangdong, Hubei, and Qinghai provinces are shown in Table 1. It can be seen in the table that the connected highways of the counties of Guangdong, Hubei, and Qinghai have been rising over the years. In 2017, the proportion of connecting expressway counties in Guangdong and Hubei exceeded 90\%, while it only exceeded 55\% in Qinghai province. 
TABLE 1: Statistics of connected highway counties for 2004-2017.

\begin{tabular}{lccc}
\hline Year & Guangdong & Hubei & Qinghai \\
\hline Sample counties & 78 & 67 & 39 \\
2004 & 31 & 17 & 8 \\
2005 & 37 & 22 & 8 \\
2006 & 40 & 23 & 9 \\
2007 & 42 & 27 & 9 \\
2008 & 42 & 30 & 9 \\
2009 & 44 & 41 & 9 \\
2010 & 54 & 45 & 9 \\
2011 & 54 & 50 & 9 \\
2012 & 54 & 51 & 10 \\
2013 & 58 & 51 & 10 \\
2014 & 59 & 62 & 10 \\
2015 & 68 & 62 & 11 \\
2016 & 70 & 64 & 13 \\
2017 & 73 & 65 & 22 \\
\hline
\end{tabular}

The explained variable is the GDP of each county, and the covariates are the population, the fixed asset investment, the fiscal expenditure, and the fiscal revenue of each county.

The descriptive statistics of the main variables are shown in Table 2. In terms of the average GDP, for Guangdong, it is 1.74 times higher than that of Hubei and 9.01 times higher than that of Qinghai. It can be seen that there are significant differences in the economic development of the three provinces. In addition, in order to reduce the heteroscedasticity of the data, a natural logarithm was used for all variables except the dummy variables. Examples of data are shown in Table 3.

\section{Parallel Trend Test Results}

There is an important assumption for the establishment of the DID method: the control group and the experimental group have the same change trend $\lambda t$ (common trend assumption), which is also known as the parallel trend assumption [34]. According to the method of Autor et al. [35], this paper estimated the DID model of the $p$-period and $q$ period before and after the opening of the expressway, which is shown as follows:

$$
L_{c t}=\alpha_{0}+\gamma_{c}+\lambda_{t}+\sum_{r=1}^{p} \beta_{-\tau} D_{c, t-\tau}+\sum_{r=0}^{p} \beta_{-\tau} D_{c, t+\tau}+\varepsilon_{a} .
$$

According to the number of samples and the general inspection needs, $\tau$ was selected to be 3 , which means the relevant conditions of three years before and after the opening of the expressway were detected. Table 4 shows the parallel trend hypothesis test results. Only Hubei province has a weak correlation with the economy in the first three years before the connection, and there is no significant difference in the other two provinces. The $p$-value of Hubei is 0.094 , which is close to rejection of the original hypothesis. The parallel trend of the three provinces is shown in Figure 1, and it can be seen that the coefficient of each province fluctuates around 0 before and after the high-speed connection, which means that the experimental group and the control group can be compared. Therefore, it is believed that the subjects are subject to the parallel trend hypothesis.

\section{Spatial Weight Matrix}

In spatial econometrics, the two most common forms of spatial weight are the adjacency matrix and the inverse distance matrix. Because the research object of this paper was the county economy, many areas were divided by the urban area of prefecture-level cities. The adjacency matrix was not suitable for this study, so the inverse distance matrix was considered. In addition, the economic distance matrix was also not used in this study due to the characteristics of the county economy.

The matrix form is shown in the following formula:

$$
W_{i j}= \begin{cases}\frac{1}{d_{i j}^{2}}, & \text { if } i \neq j, \\ 0, & \text { if } i=j .\end{cases}
$$

The distance $d_{i j}$ between the two counties is calculated according to the following equation:

$$
d_{i j}=R \cdot \arccos \left[\cos \beta_{i} \cdot \cos \beta_{j} \cdot \cos \left(\alpha_{i}-\alpha_{j}\right)+\sin \beta_{i} \cdot \sin \beta_{j}\right] .
$$

In the equation above, the longitude and latitude of county $i$ and county $j$ are $\left(\alpha_{i}, \beta_{j}\right)$ and $\left(\alpha_{i}, \beta_{j}\right)$, respectively, and $R$ is the Earth radius.

The calculation of the distance between counties is shown in Figure 2. On this basis, the inverse distance matrix required in this paper could be obtained by taking the reciprocal of the square of the distance according to equation (8).

\section{Empirical Research and Result Discussion}

\subsection{Spatial Correlation Test of Economic Growth}

7.1.1. Moran's Index (Moran's I) of Counties. In order to analyze the spatial correlation of each region, this paper calculated Moran's I of the natural logarithm of GDP of the counties of Guangdong, Hubei, and Qinghai over the years, as shown in Table 5, and the trend chart with time is shown in Figure 3.

From Table 5 and Figure 3, it can be seen that Guangdong and Qinghai show a decreasing trend in general, while Hubei reached a peak in 2008 and then declined. The above trend shows that the spatial correlation of all regions is gradually decreasing, which means that the regional economic gap in each province displays a narrowing trend.

7.1.2. The Spatial Correlation of Residuals. The spatial correlation of residuals was regressed by the OLS method, and the Moran index of residuals was calculated. The results are shown in Table 6, where it can be seen that the data of the three provinces have a significant spatial correlation. 
TABle 2: Descriptive statistics of the main variables.

\begin{tabular}{|c|c|c|c|c|c|c|}
\hline Province & Variable Name & Observed & Mean & Variance & Min & Max \\
\hline \multirow{5}{*}{ Guangdong } & GDP (10,000 yuan) & 1092 & $2,232,373$ & $3,506,064$ & 48,577 & $30,589,219$ \\
\hline & Population (10,000 people) & 1092 & 77 & 47 & 7 & 247 \\
\hline & Investment in fixed assets $(10,000$ yuan $)$ & 1092 & 846,435 & $1,236,250$ & 4151 & $10,782,942$ \\
\hline & Financial revenue $(10,000$ yuan $)$ & 1092 & 117,068 & 233,925 & 2013 & $2,248,715$ \\
\hline & Financial expenditure $(10,000$ yuan $)$ & 1092 & 233,964 & 275,213 & 10190 & $2,743,406$ \\
\hline \multirow{5}{*}{ Hubei } & GDP $(10,000$ yuan $)$ & 938 & $1,278,927$ & $1,253,906$ & 43,543 & $7,171,791$ \\
\hline & Population (10,000 people) & 938 & 66 & 33 & 8 & 165 \\
\hline & Investment in fixed assets $(10,000$ yuan $)$ & 938 & 997,944 & $1,230,851$ & 6626 & $7,993,968$ \\
\hline & Financial revenue $(10,000$ yuan $)$ & 938 & 65,093 & 85,384 & 832 & 980,543 \\
\hline & Financial expenditure $(10,000$ yuan $)$ & 938 & 200,473 & 165,795 & 7488 & 831,728 \\
\hline \multirow{5}{*}{ Qinghai } & GDP $(10,000$ yuan $)$ & 546 & 247,665 & 419,003 & 3108 & $3,272,383$ \\
\hline & Population (10,000 people) & 546 & 12 & 12 & 1 & 49 \\
\hline & Investment in fixed assets $(10,000$ yuan $)$ & 546 & 201,685 & 388,073 & 3161 & $2,922,300$ \\
\hline & Financial revenue $(10,000$ yuan $)$ & 546 & 12,100 & 25,241 & 73 & 210,302 \\
\hline & Financial expenditure (10,000 yuan) & 546 & 94,988 & 92,424 & 535 & 697,936 \\
\hline
\end{tabular}

7.2. Model Setting Test. In the space panel analysis, the specific model form needs to be tested. In this study, the LM and Robust LM tests were used to determine which of the models - the spatial lag model, the spatial error model, or the spatial Durbin model-were more suitable in this study. The Wald test and the LR test were used to determine whether the spatial Durbin model, the spatial lag model, and the spatial error model could be transformed from one another, and the Hausman test was used to determine whether it was better to use a fixed effect model or a random effect model.

7.2.1. LM and Robust LM Tests. The LM and Robust LM test results are shown in Table 7 . It can be seen from the table that both LM and Robust LM reject the original hypothesis. Therefore, the results point to the SDM.

7.2.2. Wald Test and LR Test. The results of the Wald test and the LR test are shown in Table 8. It can be seen from the table that the original assumptions of $\theta=0$ and $\theta+\rho \beta=0$ are rejected. Besides, it is believed that the SDM will not degenerate into SAR or SEM.

The results of LR inspection are shown in Table 9. It can be seen that the LR test results are similar to the Wald test results, and SDM will not degenerate into SAR or SEM.

7.2.3. The Hausman Test. The Hausman test was considered for the SDM, and the results are shown in Table 10. It can be seen from the results that Guangdong, Hubei, and Qinghai all rejected the null hypothesis at a significance level of $5 \%$. Therefore, a fixed effect model should be used for the SDM.

7.3. Model Estimation Results. The SDM was used to calculate the SDID model, and the results are shown in Table 11.

In the spatial multiple coefficients' model of the county economy in Guangdong, Hubei, and Qinghai provinces, the spatial effect coefficient $\rho$ is significant at the level of $1 \%$, which is also positive. The estimation results show that the provincial and county economies have obvious space spillover benefits. Additionally, the economic growth of one county has significantly improved the economic development of other counties.

In the spatial multiple difference model of the county economy in Guangdong province, the proportions of secondary industry, fixed asset investment, fiscal revenue, and fiscal expenditure are all significant at the $1 \%$ level, where the population is significant at the level of $5 \%$. The spatial lags of the proportion of the secondary industry, population, investment in fixed assets, fiscal revenue, and fiscal expenditure are not significant, while the space after the expressway connectivity is significant at the $1 \%$ level.

In the spatial multiple difference model of the county economy in Hubei province, the proportion of secondary industry, investment in fixed assets, fiscal revenue, fiscal expenditure, and highway connectivity are all significant at the level of $1 \%$. The value of the expressway connection factor is -0.0467 . The population and fiscal expenditure are not significant. The spatial lags of the proportion of the secondary industry, the total population, fiscal expenditure, fiscal revenue, and highway connectivity are all significant at the $1 \%$ level, while the spatial lag of fixed asset investment is not significant.

In the spatial multiple difference model of the county economy in Qinghai province, the proportions of the secondary industry and the population are both significant at the level of $1 \%$, while fixed asset investment and fiscal revenue are significant at the level of $5 \%$, and fiscal expenditure and highway connectivity are not the same. It is claimed that fixed asset investment, fiscal revenue, fiscal expenditure, and expressway connectivity are all significant at $1 \%$, and the value of the expressway connection factor is -0.0467 , while the population and fiscal expenditure are not significant. The spatial lag terms of expenditure and fiscal revenue are not significant. The spatial lag terms of the population are significant at the level of $1 \%$, and the spatial lag terms of highway connectivity are significant at the level of $5 \%$. 
TABLE 3: Descriptive statistics of the main variables.

\begin{tabular}{|c|c|c|c|c|c|c|c|c|}
\hline Province & County & Year & $\begin{array}{c}\text { GDP } \\
(10,000 \text { yuan })\end{array}$ & $\begin{array}{c}\text { Population } \\
(10,000 \text { people })\end{array}$ & $\begin{array}{l}\text { Investment in } \\
\text { fixed assets } \\
(10,000 \text { yuan })\end{array}$ & $\begin{array}{c}\text { Financial } \\
\text { revenue } \\
(10,000 \text { yuan })\end{array}$ & $\begin{array}{c}\text { Financial } \\
\text { expenditure } \\
(10,000 \text { yuan })\end{array}$ & $\begin{array}{l}\text { Expressway } \\
\text { Connection }\end{array}$ \\
\hline \multirow{16}{*}{ Guangdong } & \multirow{14}{*}{ Dongyuan } & 2004 & 242,357 & 52 & 127,567 & 6833 & 53,237 & 0 \\
\hline & & 2005 & 245,098 & 53 & 139,740 & 10,257 & 62,442 & 1 \\
\hline & & 2006 & 316,992 & 54 & 203,670 & 15,703 & 73,389 & 1 \\
\hline & & 2007 & 417,860 & 52 & 242,902 & 20,166 & 97,459 & 1 \\
\hline & & 2008 & 512,531 & 54 & 145,533 & 22,789 & 107,439 & 1 \\
\hline & & 2009 & 511,182 & 57 & 162,857 & 26,045 & 125,383 & 1 \\
\hline & & 2010 & 595,479 & 57 & 218,948 & 30,741 & 145,208 & 1 \\
\hline & & 2011 & 743,345 & 59 & 185,261 & 40,021 & 173,153 & 1 \\
\hline & & 2012 & 794,021 & 55 & 185,261 & 47,406 & 191,835 & 1 \\
\hline & & 2013 & 863,663 & 56 & 571,838 & 60,272 & 231,619 & 1 \\
\hline & & 2014 & 979,803 & 59 & 668,479 & 73,540 & 295,969 & 1 \\
\hline & & 2015 & $1,006,351$ & 59 & 752,427 & 79,807 & 323,145 & 1 \\
\hline & & 2016 & $1,046,923$ & 59 & 917,610 & 83,063 & 393,346 & 1 \\
\hline & & 2017 & $1,137,344$ & 59 & $1,112,709$ & 88,127 & 402,662 & 1 \\
\hline & \multirow{3}{*}{ Fengshun } & 2004 & 263,915 & 67 & 19,353 & 6376 & 41,655 & 1 \\
\hline & & 2005 & 314,213 & 67 & 68,323 & 9431 & 46,566 & 1 \\
\hline & & & & & $\ldots$ & & & \\
\hline \multirow{17}{*}{ Hubei } & \multirow{14}{*}{ Danjiangkou } & 2004 & 408,179 & 49 & 17,467 & 15,058 & 15,058 & 1 \\
\hline & & 2005 & 421,648 & 49 & 81,079 & 16,861 & 45,892 & 1 \\
\hline & & 2006 & 480,100 & 49 & 194,173 & 228,63 & 57,617 & 1 \\
\hline & & 2007 & 545,100 & 50 & 148,877 & 25,462 & 72,882 & 1 \\
\hline & & 2008 & 676,300 & 50 & 242,090 & 30,444 & 98,355 & 1 \\
\hline & & 2009 & 757,106 & 50 & 358,945 & 45,158 & 183,822 & 1 \\
\hline & & 2010 & 921,359 & 46 & 493,961 & 119,758 & 265,885 & 1 \\
\hline & & 2011 & $1,083,752$ & 46 & 698,792 & 157,918 & 329,081 & 1 \\
\hline & & 2012 & $1,300,165$ & 46 & 970,683 & 275,883 & 379,843 & 1 \\
\hline & & 2013 & $1,507,151$ & 46 & $1,282,892$ & 221,465 & 429,533 & 1 \\
\hline & & 2014 & $1,658,103$ & 46 & $1,595,100$ & 115,348 & 311,557 & 1 \\
\hline & & 2015 & $1,830,222$ & 46 & $1,883,854$ & 132,058 & 415,490 & 1 \\
\hline & & 2016 & $1,986,835$ & 46 & $2,278,400$ & 129,504 & 445,362 & 1 \\
\hline & & 2017 & $2,234,856$ & 46 & $2,507,371$ & 149,238 & 485,865 & 1 \\
\hline & \multirow{3}{*}{ Yunmeng } & 2004 & 469,066 & 58 & 24,700 & 13,065 & 27,340 & 0 \\
\hline & & 2005 & 469,623 & 58 & 99,471 & 13,376 & 30,488 & 1 \\
\hline & & & & & $\ldots$ & & & \\
\hline \multirow{16}{*}{ Gansu } & \multirow{14}{*}{ Dongxiang } & 2004 & 33,537 & 27 & 122 & 766 & 16,674 & 1 \\
\hline & & 2005 & 43,921 & 27 & 151 & 738 & 21,083 & 1 \\
\hline & & 2006 & 48,509 & 27 & 179 & 781 & 31,366 & 1 \\
\hline & & 2007 & 54,146 & 27 & 233 & 970 & 46,654 & 1 \\
\hline & & 2008 & 63,095 & 27 & 336 & 1224 & 67,234 & 1 \\
\hline & & 2009 & 71,534 & 28 & 629 & 2090 & 86,135 & 1 \\
\hline & & 2010 & 79,364 & 32 & 814 & 2281 & 104,517 & 1 \\
\hline & & 2011 & 97,882 & 29 & 1192 & 2800 & 175,700 & 1 \\
\hline & & 2012 & 119,574 & 32 & 1755 & 5519 & 197,341 & 1 \\
\hline & & 2013 & 127,197 & 33 & 1899 & 10,689 & 188,671 & 1 \\
\hline & & 2014 & 150,854 & 35 & 2289 & 12,268 & 193,393 & 1 \\
\hline & & 2015 & 162,743 & 34 & 2613 & 6878 & 217,323 & 1 \\
\hline & & 2016 & 173,012 & 35 & 2830 & 7602 & 241,730 & 1 \\
\hline & & 2017 & 188,803 & 36 & 1148 & 8059 & 292,944 & 1 \\
\hline & \multirow[b]{2}{*}{ Liangdang } & 2004 & 16,719 & 5 & 15.35 & 448 & 7512 & 0 \\
\hline & & 2005 & 19,990 & 5 & 18 & 461 & 9881 & 0 \\
\hline
\end{tabular}

It can be seen from the comparison that the relationship between the expressway connection and economic growth is not significant or plays a certain negative role, while the space spillover effect of the expressway connection is significant and positive. Although the connection of expressways has no direct positive impact on the economic growth of directly connected counties, it has a positive effect on the county economy in the entire region.

According to the study of spatial econometrics, the parameter estimation results obtained in Table 11 are biased. In order to more deeply understand the impact of highway connectivity on the county economy, the results needed to be 
TABle 4: Parallel trend test results.

\begin{tabular}{lccr}
\hline Variables & Guangdong & Hubei & Qinghai \\
\hline 3 years prior & $-0.0447(-1.61)$ & $-0.0394^{*}(-1.68)$ & $-0.106(-0.54)$ \\
2 years prior & $-0.015(-0.41)$ & $-0.0309(-0.97)$ & $0.0372(0.19)$ \\
1 year prior & $-0.00822(-0.17)$ & $-0.0401(-1.25)$ & $0.099(0.37)$ \\
Connect year & $0.0544(1.20)$ & $-0.0285(-1.04)$ & $0.105(0.41)$ \\
1 year after & $-0.0117(-0.37)$ & $-0.00143(-0.05)$ & $-0.105(-0.54)$ \\
2 years after & $0.0413(1.29)$ & $0.000272(0.01)$ & $-0.155(-1.16)$ \\
3 years after & $0.0277(0.96)$ & $-0.00641(-0.23)$ & $-0.0496(-0.74)$ \\
Constants & $14.41^{* * *}(407.36)$ & $14.35^{* * *}(385.88)$ & $12.22^{* * *}(163.3)$ \\
\hline
\end{tabular}

Note. ${ }^{*}$ for $p<0.05,{ }^{* *}$ for $p<0.01$, and ${ }^{* * *}$ for $p<0.001 ; t$ statistics in parentheses.

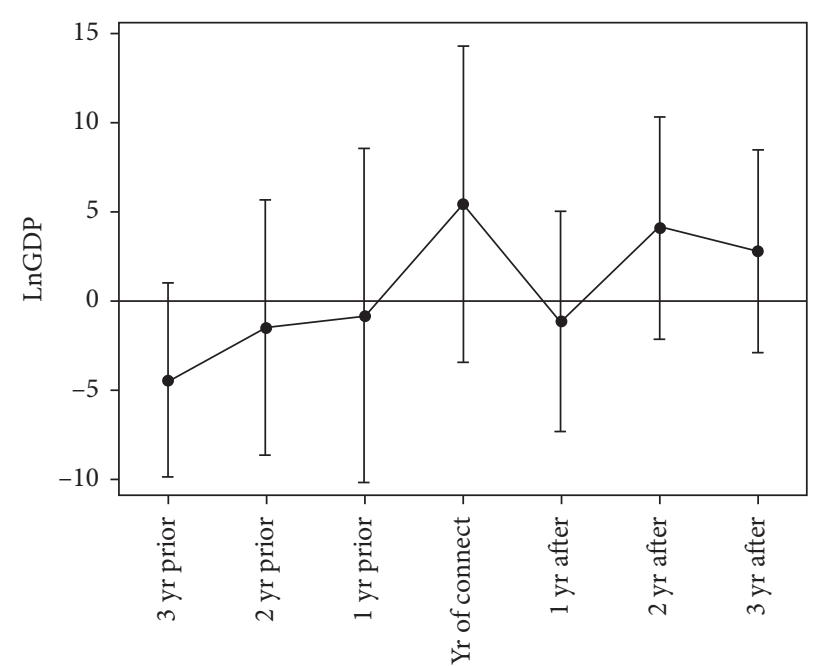

(a)

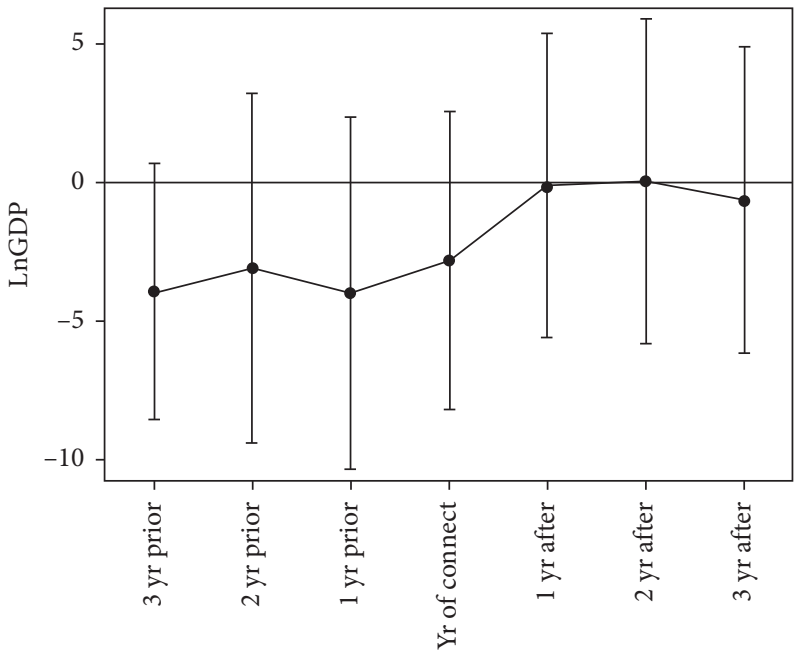

(b)

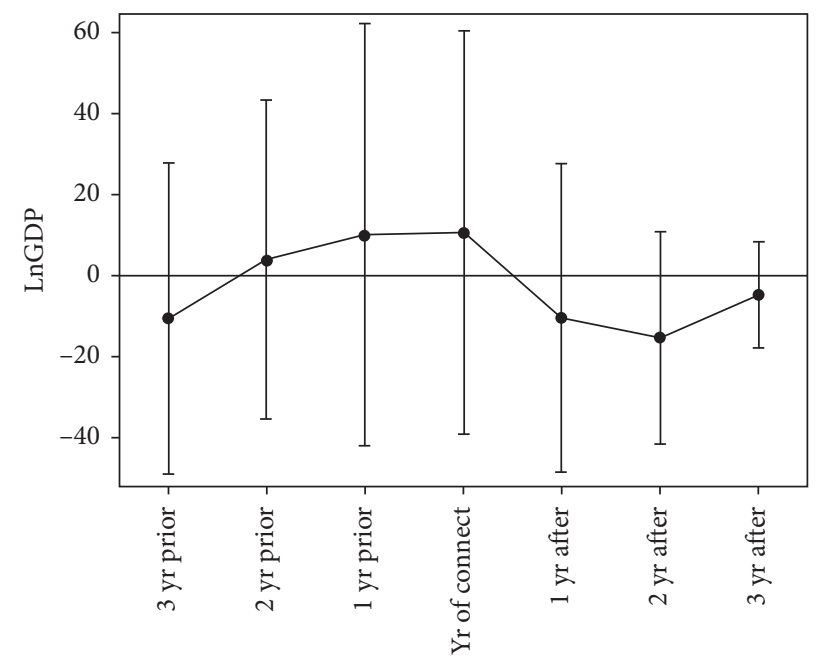

(c)

FIgURE 1: The parallel trend of Guangdong, Hubei, and Qinghai provinces. (a) Guangdong. (b) Hubei. (c) Qinghai. 


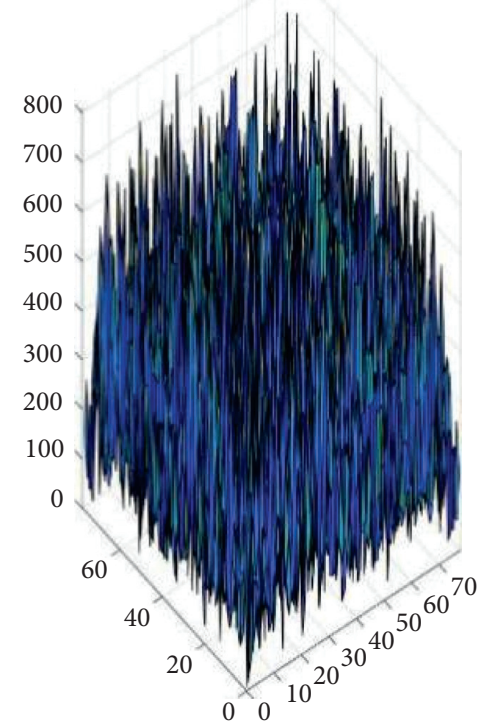

(a)

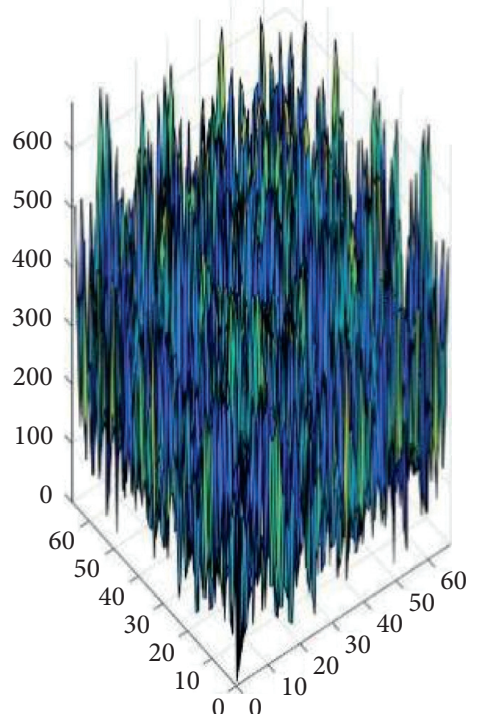

(b)

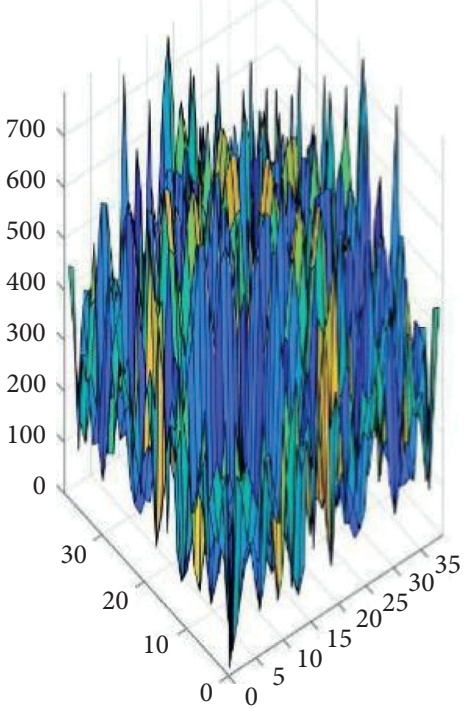

(c)

FIgURE 2: Schematic diagram of the distance matrix of counties by province. (a) Guangdong. (b) Hubei. (c) Gansu.

Table 5: Moran's index (Moran's I) of the GDP of the counties of Guangdong, Hubei, and Qinghai in 2004-2017.

\begin{tabular}{lccc}
\hline Year & Guangdong & Hubei & Qinghai \\
\hline 2004 & 0.494 & 0.315 & 0.453 \\
2005 & 0.495 & 0.306 & 0.467 \\
2006 & 0.486 & 0.315 & 0.45 \\
2007 & 0.47 & 0.33 & 0.469 \\
2008 & 0.462 & 0.349 & 0.442 \\
2009 & 0.462 & 0.328 & 0.431 \\
2010 & 0.441 & 0.327 & 0.44 \\
2011 & 0.438 & 0.33 & 0.434 \\
2012 & 0.46 & 0.325 & 0.424 \\
2013 & 0.446 & 0.317 & 0.448 \\
2014 & 0.452 & 0.307 & 0.459 \\
2015 & 0.451 & 0.304 & 0.443 \\
2016 & 0.453 & 0.303 & 0.434 \\
2017 & 0.462 & 0.414 \\
\hline
\end{tabular}

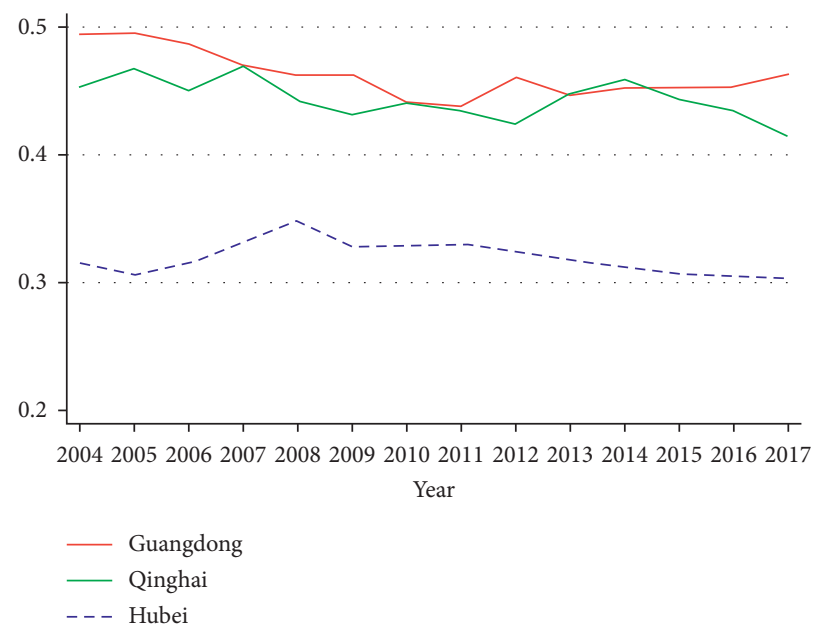

Figure 3: Chart of Moran's I over time. 
TABLE 6: OLS regression residual Moran index.

\begin{tabular}{lcccccc}
\hline Province & Guangdong & $p$ value & Hubei & $p$ value & Qinghai & $p$ value \\
\hline Results & 5.516 & 0.000 & 112.477 & 0.000 & 92.711 & 0.000 \\
\hline
\end{tabular}

TABLE 7: The LM and Robust LM test results.

\begin{tabular}{lccccc}
\hline Index & Guangdong & $p$ value & Hubei & $p$ value & Qinghai \\
\hline LM-error & 28.851 & 0 & 112.477 & 0 & 92.711 \\
Robust LM-error & 15.18 & 0 & 70.034 & 0 & 69.639 \\
LM-lag & 26.59 & 0 & 66.034 & 0 & 0 \\
Robust LM-lag & 12.919 & 0 & 23.591 & 0 & 27.328 \\
\hline
\end{tabular}

TABLE 8: The Wald test results.

\begin{tabular}{lcccccc}
\hline Index & Guangdong & $p$ value & Hubei & $p$ value & Qinghai & $p$ value \\
\hline$H 0: \theta=0$ & 87.04 & 0 & 69.99 & 0 & 33.75 & 0 \\
$H 0: \theta+\rho \beta=0$ & 46.37 & 0 & 87.83 & 0 & 51.53 & 0 \\
\hline
\end{tabular}

TABLE 9: The LR test results.

\begin{tabular}{lcccccc}
\hline Index & Guangdong & $p$ value & Hubei & $p$ value & Qinghai & $p$ value \\
\hline SDM/SAR & 45.52 & 0 & 68.78 & 0 & 33.23 & 0 \\
SDM/SEM & 158.69 & 0 & 178.46 & 0 & 110.57 \\
\hline
\end{tabular}

TABLE 10: The Hausman test results.

\begin{tabular}{lcccccc}
\hline Index & Guangdong & $p$ value & Hubei & $p$ value & Qinghai & $p$ value \\
\hline$H 0:$ random & 115.51 & 0 & 17.22 & 0.016 & 25.25 & 0.0007 \\
\hline
\end{tabular}

TABLE 11: The estimation results of the spatial difference-in-differences (SDID) model.

\begin{tabular}{|c|c|c|c|}
\hline Variables & Guangdong & Hubei & Qinghai \\
\hline secper & $0.4649^{* * *}(9.00)$ & $0.6488^{* * *}(9.17)$ & $1.4044^{* * *}(14.47)$ \\
\hline total_pop_ln & $0.1014^{* *}(2.32)$ & $0.0494(0.3)$ & $-0.1797^{* * *}(-2.97)$ \\
\hline invest_ln & $0.0402^{* * *}(5.55)$ & $0.0362 * * *(4.56)$ & $0.0394^{* *}(2.35)$ \\
\hline fin_reve_ln & $0.1035^{* * *}(6.75)$ & $0.0827^{* * *}(6.41)$ & $0.044^{* *}(2.16)$ \\
\hline fin_exp_ln & $0.1646^{* * *}(6.58)$ & $0.0232(1.36)$ & $-0.0434(-1.49)$ \\
\hline $\exp$ & $-0.0127(-0.87)$ & $-0.0467^{* * *}(-4.02)$ & $0.0276(0.6)$ \\
\hline $\mathrm{W} *$ secper & $-0.1501(-1)$ & $-1.3039^{* * *}(-6.82)$ & $-0.2616(-1.01)$ \\
\hline $\mathrm{W} *$ total_pop_ln & $0.0413(0.25)$ & $-1.6083^{* * *}(-3.7)$ & $-0.6312^{* * *}(-3.56)$ \\
\hline $\mathrm{W} *$ invest_ln & $-0.0316(-1.64)$ & $0.0194(0.84)$ & $-0.022(-0.64)$ \\
\hline $\mathrm{W} *$ fin_reve_ln & $-0.0127(-0.34)$ & $0.1518^{* * *}(4.18)$ & $-0.0172(-0.5)$ \\
\hline $\mathrm{W} *$ fin_exp_ln & $0.0159(0.32)$ & $0.2135^{* * *}(4.05)$ & $0.152(1.49)$ \\
\hline $\mathrm{W} * \exp$ & $0.1492^{* * *}(4.22)$ & $0.109^{* * *}(2.97)$ & $0.3204^{* *}(2.22)$ \\
\hline rho & $0.2644^{* * *}(5.02)$ & $0.3997^{* * *}(6.99)$ & $0.3292^{* * *}(4.55)$ \\
\hline sigma2_e & $0.0129^{* * *}(23.26)$ & $0.009^{* * *}(21.46)$ & $0.031^{* * *}(16.38)$ \\
\hline $\log L$ & 820.1518 & 870.7909 & 168.6213 \\
\hline
\end{tabular}

Note. ${ }^{*} p<0.05,{ }^{* *} p<0.01$, and ${ }^{* * *} p<0.001 ; t$ statistics in parentheses. 
TABle 12: Direct, indirect, and total effects.

\begin{tabular}{lcccccc}
\hline Variables & Guangdong & $\begin{array}{c}p \\
\text { value }\end{array}$ & Hubei & $\begin{array}{c}p \\
\text { value }\end{array}$ & Qinghai & $\begin{array}{c}p \\
\text { value }\end{array}$ \\
\hline exp & -0.0127 & 0.382 & -0.0467 & 0.000 & 0.0276 & 0.548 \\
W * exp & 0.1492 & 0.000 & 0.1090 & 0.003 & 0.3204 & 0.026 \\
$\begin{array}{l}\text { Direct } \\
\text { effect }\end{array}$ & -0.0065 & 0.650 & -0.0413 & 0.000 & 0.0494 & 0.308 \\
$\begin{array}{l}\text { Indirect } \\
\text { effect }\end{array}$ & 0.1963 & 0.000 & 0.1517 & 0.016 & 0.4940 & 0.033 \\
$\begin{array}{l}\text { Total } \\
\text { effect }\end{array}$ & 0.1898 & 0.000 & 0.1104 & 0.091 & 0.5434 & 0.032 \\
\hline
\end{tabular}

further decomposed into direct and indirect effects (also known as spillover effects). During the analysis, the direct effect reflected the impact of highway connectivity on the economic growth of connected counties, while the indirect effect reflected its impact on the economic growth of other counties. The decomposition results of direct and indirect effects are shown in Table 12.

It is shown from Table 12 that the direct and indirect effects of the three provinces' highway connections on the county economy are not similar. The direct effect of Guangdong is close to 0 , which is also not significant in the model. The value of the indirect effect is 0.1963 , of which the total effect is 0.1898 . The value of the direct effect of Hubei is -0.0413 , of which the indirect effect is 0.1517 and the total effect is 0.1104 . The direct effect of Qinghai province is positive, but not significant. The value of the indirect effect is 0.4940 and the total effect is 0.5434 . From the above results, it can be found that the expressway connection has no significant impact on the economic growth of the connected counties and even has a certain negative impact. However, it has a significant space spillover effect on adjacent areas and benefits the overall regional economic growth. The indirect impact of the value is affected by many factors, such as the economic development situation of various places and the existing level of transportation infrastructure development.

\section{Conclusion}

Highways are designed to connect provincial capital cities with populations of more than 500,000. As a side effect, a large number of surrounding county towns are connected to large urban agglomerations, so county economies are affected by the spillover and siphon effects of larger cities. This article validated Faber's research results [16]. The completion of an expressway will bring about a decline in the GDP growth rate of nontarget surrounding areas. However, from the perspective of the overall development of the county economy, the connection of an expressway has a significant spillover effect. The effect has a greater promotion effect on the overall regional economic growth, which is ignored by the traditional DID analysis method.

Both the economic development of the county and its relationship with related factors show obvious spatial correlations. The use of the spatial DID model can result in an improvement in terms of the dependence of the traditional DID model on the SUTVA assumption and can more accurately assess the impact of highway connection on the county economy.
The total effect of the expressway connectivity on the county economy in each province is positive, but the impact on the connected counties is negative or is even not significant, which is similar to the results of previous scholars' estimations based on the DID model. The reason for this is considered to be related to the economic siphon effect formed after rapid transportation infrastructure construction. This verifies the two-stage conclusion of the impact of the decline in transportation costs in the new economic geography: the first stage widens the regional economy and income gap; in the second stage, the industry spreads to low-income regions. Therefore, it can be seen that roads and other transportation infrastructure have spatial spillover effects, but it is uncertain whether the spillover effects are positive.

Comparing the data from the Guangdong, Hubei, and Qinghai provinces, it has been shown that the impact of expressway connectivity on the county economy of Qinghai province is more obvious than that of the other two provinces, which is because of Qinghai's relatively low level of economic development and proportion of expressway connectivity. This paper used a spatial DID model to eradicate the dependence of the traditional DID model on the SUTVA assumption and to effectively estimate the space spillover effect of highway connectivity. Therefore, it has more scientifically and comprehensively analyzed the impact of highway connectivity on the area.

The construction of highways requires the central and local governments at all levels to invest a lot of manpower, material resources, and funds, so it is of practical significance to effectively evaluate the economic effects of highways and other infrastructure construction. The research in this paper proves that counties with more connections can effectively promote the efficient flow of factors and the overall development of the county economy. At the same time, there is a certain degree of uncertainty regarding the impact of the overall development of expressways and its own industrial characteristics on specific counties. From the analysis results, it can be seen that the completion and opening of the expressway to traffic does not directly promote the economic growth of the connected counties, but it has a significant role in promoting the county economy in the province as a whole. According to the two-stage conclusion of the impact of declining transportation costs, the economy of lagging counties may experience a period of negative impact after they are connected to expressways. Therefore, the management department should adjust the industrial composition in time according to the different stages of county development to deal with the impact of the adjustment of regional economic distribution. Expressway construction has always been one of the important means for China to stimulate economic development, and the research results of this article provide evidence for the supporting role of expressways on the county economy, which will provide a basis for better expressway development policies.

\section{Data Availability}

The data used to support the findings of this study are included within the article. 


\section{Conflicts of Interest}

The authors declare that they have no conflicts of interest.

\section{References}

[1] L. Peng, "The influence of expressway on social and economic development," China's Foreign Trade, vol. 499, pp. 59-61, 2011.

[2] X. Sun, Z. Wang, and G. Zhang, "Is there structural bonus in the growth of county total factor productivity?-evidence of panel data of 1869 counties in China," Journal of Zhongnan University of Economics and Law, vol. 255, pp. 74-83, 2017.

[3] D. A. Aschauer, "Is public expenditure productive?," Journal of Monetary Economics, vol. 23, no. 2, pp. 177-200, 1989.

[4] M. G. Boarnet, "Spillovers and the locational effects of public infrastructure," Journal of Regional Science, vol. 38, no. 3, pp. 381-400, 1998.

[5] J. Khadaroo and B. Seetanah, "Transport and economic performance: the case of Mauritius," Journal of Transport Economics and Policy, vol. 42, no. 2, pp. 255-267, 2008.

[6] A. J. Khadaroo and B. Seetanah, "Transport infrastructure and foreign direct investment," Journal of International Development, vol. 22, no. 1, pp. 103-123, 2010.

[7] R. P. Pradhan, N. R. Norman, Y. Badir, and B. Samadhan, "Transport infrastructure, foreign direct investment and economic growth interactions in India: the ARDL bounds testing approach," Procedia - Social and Behavioral Sciences, vol. 104, pp. 914-921, 2013.

[8] P. C. Sanchez and M. G. Albert, "Transport infrastructures, co2 emissions and economic growth: new evidence from oecd countries," International Journal of Transport Economics, vol. 42, no. 2, pp. 251-268, 2015.

[9] J. Chi, "Transport infrastructure and macroeconomic performance in European countries," Transportation Research Record: Journal of the Transportation Research Board, vol. 2530, no. 1, pp. 84-92, 2015.

[10] R. Crescenzi, M. Di Cataldo, and A. Rodríguez-Pose, "Government quality and the economic returns of transport infrastructure investment in European Regions," Journal of Regional Science, vol. 56, no. 4, pp. 555-582, 2016.

[11] G. Kalra, V. Chotia, and A. Goel, "Investigating the relationship between transport infrastructure and economic growth: the case of India," Indian Journal of Economics and Development, vol. 12, no. 2, pp. 315-320, 2016.

[12] Y. T. Mohmand, A. Wang, and A. Saeed, "The impact of transportation infrastructure on economic growth: empirical evidence from Pakistan," Transportation Letters, vol. 9, no. 2, pp. 63-69, 2017.

[13] B. Yapicioglu, O. N. Mogbo, and I. Yitmen, "Innovative strategies for transport policies in infrastructure development: Nigerian stakeholders' perspective," International Journal of Civil Engineering, vol. 15, no. 5, pp. 747-761, 2017.

[14] S. Saidi, M. Shahbaz, and P. Akhtar, "The long-run relationships between transport energy consumption, transport infrastructure, and economic growth in MENA countries," Transportation Research Part A: Policy and Practice, vol. 111, pp. 78-95, 2018.

[15] S. Tong, "Research on the relationship between economic growth and road traffic infrastructure in inner Mongolia," in Proceedings of the 4th International Conference on Advances in Energy Resources and Environment Engineering. IOP Conference Series-Earth and Environmental Science, vol. 237, Chengdu, China, December 2019.
[16] X. Wang, S. Liu, and W. Qi, "Mega-towns in China: their spatial distribution features and growth mechanisms," Journal of Geographical Sciences, vol. 30, no. 7, pp. 1060-1082, 2020.

[17] N. Baumsnow, J. V. Henderson, M. A. Turner et al., "Does investment in national highways help or hurt hinterland city growth?," Journal of Urban Economics, vol. 115, pp. 103-124, 2020.

[18] I. Herzog, "National transportation networks, market access, and regional economic growth," Journal of Urban Economics, vol. 3, pp. 103-316, 2021.

[19] C. Liu and L. Zhou, "The impact of transportation infrastructure on ECONOMIC development: evidence from counties in China," Economic Science, vol. 171, no. 2, pp. 55-67, 2014.

[20] B. Faber, "Trade integration, market size, and industrialization: evidence from China's national trunk highway system," The Review of Economic Studies, vol. 81, no. 3, pp. 1046-1070, 2014.

[21] X. Dong and Y. Liu, "Does highway promote economy development? Evidence from the China national highway construction during 2004-2013," Nankai Economic Studies, vol. 4, pp. 3-20, 2018.

[22] C. Zheng, "Analysis of the impact of China's high-speed railway on urban economic development-based on the empirical study of prefecture-level cities at high-speed railway stations," Social Scientist, vol. 3, pp. 14-21, 2019.

[23] Y. Wang and M. Nian, "Does the high-speed railway drive regional economic development?," Shanghai Journal of Economics, vol. 2, pp. 84-93, 2014.

[24] H. Li, L. Tjia, and S. Hu, "Impact of China's high-speed railway on the economic agglomeration andEqualization of cities along the line," The Journal of Quantitative \& Technical Economics, vol. 11, pp. 127-143, 2016.

[25] D. Fang and M. Sun, "Evaluation of the impact of high-speed railways on the economic development ofthe Yangtze River Delta city group-an empirical study based on the DID model," East China Economic Management, vol. 30, no. 230, pp. 48-53, 2016.

[26] Z. Fan, H. Zhang, and J. Chen, "Spillover effect and siphon effect of public transport on the HousingMarket: taking the metro as an example," China Industrial Economics, vol. 362, pp. 100-118, 2018.

[27] M. S. Delgado and R. J. G. M. Florax, "Difference-in-differences techniques for spatial data: local autocorrelation and spatial interaction," Economics Letters, vol. 137, pp. 123-126, 2015.

[28] L. W. Miratrix and P. R. Rosenbaum, "Design of observational studies," Psychometrika, vol. 79, no. 3, pp. 540-542, 2014.

[29] C. F. Manski, "Identification of treatment response with social interactions," The Econometrics Journal, vol. 16, no. 1, pp. 1-23, 2013.

[30] J. Dubé, D. Legros, M. Thériault, and F. Des Rosiers, “A spatial Difference-in-Differences estimator to evaluate the effect of change in public mass transit systems on house prices," Transportation Research Part B: Methodological, vol. 64, pp. 24-40, 2014.

[31] A. L. S. Chagas, C. R. Azzoni, and A. N. Almeida, "A spatial difference-in-differences analysis of the impact of sugarcane production on respiratory diseases," Regional Science and Urban Economics, vol. 59, pp. 24-36, 2016.

[32] Y. Sunak and R. Madlener, "The impact of wind farm visibility on property values: a spatial difference-in-differences analysis," Energy Economics, vol. 55, pp. 79-91, 2016. 
[33] T. Zhou, Z. Lu, and T. Sun, "Can the development of rail transit promote Beijing's industrial proliferation?," Research on Economics and Management, vol. 7, no. 12, pp. 90-97, 2016.

[34] D. Card and A. B. Krueger, "Minimum wages and employment: a case study of the fast-food industry in New Jersey and Pennsylvania: reply," American Economic Review, vol. 90, no. 5, pp. 1397-1420, 2000.

[35] D. H. Autor, J. J. Donohue, and S. J. Schwab, "The costs of wrongful-discharge laws," Review of Economics and Statistics, vol. 88, no. 2, pp. 211-231, 2006. 